Research Article

\title{
Stress Distribution and Gas Concentration Evolution during Protective Coal Seam Mining
}

\author{
Xingang Niu $\mathbb{D}^{1,2,3,4}$ Biming Shi, ${ }^{1,2}$ Zhigang Zhang, ${ }^{3,4}$ and Yongjiang Zhang ${ }^{3,4}$ \\ ${ }^{1}$ State Key Laboratory of Mining Response and Disaster Prevention and Control in Deep Coal Mines, \\ Anhui University of Science and Technology, Huainan, Anhui 232001, China \\ ${ }^{2}$ School of Energy and Security, Anhui University of Science and Technology, Huainan, Anhui 232001, China \\ ${ }^{3}$ State Key Laboratory of the Gas Disaster Detecting Preventing and Emergency Controlling, \\ China Coal Technology and Engineering Group Chongqing Research Institute, Chongqing 400037, China \\ ${ }^{4}$ Gas Research Branch, China Coal Technology and Engineering Group Chongqing Research Institute, Chongqing 400037, China
}

Correspondence should be addressed to Xingang Niu; xingang202012@163.com

Received 23 December 2020; Revised 31 January 2021; Accepted 19 February 2021; Published 1 March 2021

Academic Editor: Zhijie Wen

Copyright (c) 2021 Xingang Niu et al. This is an open access article distributed under the Creative Commons Attribution License, which permits unrestricted use, distribution, and reproduction in any medium, provided the original work is properly cited.

Coal and gas burst is one of the significant and catastrophic hazards in underground longwall operations. To date, the protective coal seam mining has been recognized as the most effective mining method for minimizing or even avoiding the effect of the coal and gas burst. In this paper, numerical modelling and field test were carried out for the longwall operation in Qidong Coal Mine in order to investigate the induced stress and coal seam gas drainage performance in the protected coal seam after the complete extraction of the protective coal seam. It was found that four stress zones can be classified in the protected coal seam being the original stress zone, stress concentration zone, stress relief zone, and recompaction zone. In addition, the monitoring data of gas concentration and volume change in the field agree well with the numerical modelling results.

\section{Introduction}

China has one of the largest mining industries in the world and due to the increasing complex geological conditions and mining depth, the frequency of the coal and gas burst occurrence tends to increase. The number of incidents resulted by the coal and gas burst in China accounts for $40 \%$ globally. As the mining depth increases, the geological stress increases and so does the concentration of the coal seam gas. The existing mines that used to have low gas concentration are now challenged by the increasing gas concentration as the mining operation moves deeper. In addition, the new mines face the challenge by high gas concentration from the beginning of the operation. The incidents caused by the coal and gas burst have been occurring from time to time [1-3]. The protective coal seam mining has been recognized as one of the most efficient mining methods in order to minimize or even prevent the coal and gas burst hazards and hence it has been investigated extensively globally. Wang et al. [4] confirmed that the protective coal seam mining is the most economical efficient method to prevent the coal and gas burst through analytical and field testing research. Wang et al. [5] pointed out that the coal seam gas predrainage is the most efficient way to eliminate the risk associated with coal and gas burst. Chen et al. [6-8] carried out research to investigate the permeability of the coal seam during mining operation and hence revealed that such a permeability would increase significantly due to the effect of stress relief and fractures in the seam resulted by mining activities. Nima et al. [9] identified the creep behaviour of the coal seam playing a significant role in the permeability of coal seam and gas drainage. Jin et al. [10] investigated the effect of the protective coal seam mining on the gas management through numerical modelling, statistical analysis, and residual gas analysis. Yuan et al. [11] investigated the pillar stability and change of permeability in coal seam during mining operation and hence concluded that the distance between adjacent coal pillars is a significant factor in stress 
relief in the protective coal seam and permeability change of coal seam. Li [12] pointed out compared to the protective coal seam mining, the extraction of the thin coal seam would minimize the coal and gas burst hazards and it is costly and timely economical. Wang et al. [13] used the soft coal seam adjacent to the thick seam as the protective coal seam. He et al. [14] investigated the permeability change in the upper coal seam during the extraction of the lower protective coal seam and developed an analytical model to simulate such a change during mining operation. Yuan et al. [15] conducted a series of laboratory tests simulating the filed condition to investigate the role of the distance between adjacent coal seams in protective coal seam mining. Shi and Liu [16] concluded that the distance between the protective and protected coal seams could affect the stress relief and deformation of the protected coal seam significantly. The deformation would tend to decrease as the distance increases and hence the crack initiation and propagation would be limited. Fang et al. [17] investigated the effect of the dip angle on the stress relief and deformation of the coal seam during the extraction of the protective coal seam and they concluded that as the dip angle increases, the deformation and damage in the overlying coal seam tend to decrease. Qin et al. [18] believed the computational fluid dynamics (CFD) is the optimized method for coal seam gas drainage design. Cao et al. [19] used a numerical model to simulate the stressstrain relationship in the lower protective coal seam during the protective coal seam mining operation and hence mapped out the stress relief zone which was further validated by theoretical approaches. Xue et al. [20] investigated the stress relief and permeability increase in the protective coal seam during mining operation and hence developed physical models that capture subsidence zone and fracture distribution zone in the protective coal seam. Wang et al. [21] conducted parametric studies to analyse the effect of a range of parameters associated with longwall panel design on the permeability change in the coal seam. Zhang et al. [22] conducted numerical simulation to study the influence of the overlying coal seam's stress and strain during the mining of the lower coal seam and then concluded that the stress distribution would be categorized into three zones being the original stress zone where no deformation was detected, stress concentration zone where compression occurs, and stress relief zone where tensile failure occurs. It should be noted that the large deformation occurs in the stress relief zone.

Overall, it can be seen that extensive research has been carried out to investigate the effect of the protective coal seam mining on prevention of the coal and gas burst in underground longwall mining. However, the research on the stress distribution in the coal seams overlying and underlying the protective coal seam is limited, either theoretical or numerical work. In this research, through the field testing and numerical modelling, the stress distribution in the protective and protected coal seams was analysed. It was found that the numerical model results agree well with field monitoring data.

\section{Stress Distribution in Overlying Protective Coal Seam}

2.1. Input Parameters. Qidong Coal Mine is located in Suzhou City, Anhui Province, China (see Figure 1). There are seven seams that are economically feasible to be mined including seams $6_{1}, 6_{2}, 6_{3}, 7_{1}, 8_{1}, 8_{2}$, and 9 . At present, seams $61,7_{1}, 8_{2}$, and 9 are being extracted with average seam thicknesses $32.13,31.95$, and $10.29 \mathrm{~m}$. The mining direction is downwards where seam $\sigma_{1}$ is the first seam to be mined. All the input parameters were obtained from longwall panel $6_{1} 35$ in the protective coal seam $6_{1}$. The average seam thickness is $1.93 \mathrm{~m}$. The average dip angle is $13^{\circ}$. The depth of cover ranges from 520 to $598 \mathrm{~m}$. The panel length is $1770 \mathrm{~m}$ and face width is $200 \mathrm{~m}$. The protected coal seam $7_{1}$ has an average sea thickness of $1.42 \mathrm{~m}$. The gas concentration is as high as $1.69 \mathrm{~m}^{3} / \mathrm{t}$ and outburst pressure can be up to $1.9 \mathrm{MPa}$. It can be confirmed that seam $\sigma_{1}$ is less likely to have gas burst occurred than seam $7_{1}$, and therefore, seam $6_{1}$ is extracted first to protect seam $7_{1}$ such that the elastic energy can be reduced and permeability can be increased in seam $7_{1}$. Such a strategy can aid the further gas drainage in seam $7_{1}$ and hence reduce its gas concentration. The distance between seams $6_{1}$ and $7_{1}$ ranges from 40 to $46 \mathrm{~m}$ with an average $44 \mathrm{~m}$.

Based on the aforementioned parameters for longwall panel 6135 , the numerical model can be established to simulate the field condition as seen in Figure 2. Based on such a model, the stress distribution, stress relief area, and deformation in the overlying and underlying coal seams can be simulated.

In the model, $X$ axis is along the dip direction and $Y$ axis is along the longwall panel length. The size of the model is $X \times Y \times Z=400 \mathrm{~m} \times 400 \mathrm{~m} \times 289.7 \mathrm{~m}$. The longwall panel width and length in the model are $100 \mathrm{~m}$ and $200 \mathrm{~m}$, respectively. Constrain the velocities in the $x, y$, and $z$ directions of the bottom boundary nodes, and constrain the horizontal velocity on the boundaries on both sides of $x$. The panel retreat starts from where $Y=100 \mathrm{~m}$, and the longwall face moves $5 \mathrm{~m}$ at each step during modelling, and therefore, in total 40 steps, it would be simulated. Fixed boundary was assigned for bottom and sides, whereas free boundary was for the top of the model. The vertical stress from overburden is mainly resulted by its weight and hence $10 \mathrm{MPa}$ was assigned at the top boundary considering the overburden thickness is around $400 \mathrm{~m}$.

In total, 326,400 meshes and 341,172 nodes were generated. It is noteworthy that the mesh around the roof and floor of seam $6_{1}$ was finer for pursuing the simulation. All the input parameters in the numerical model were determined by measurement and monitoring on the site (see Table 1).

2.2. Stress Distribution in the Roof and Floor of Protective Coal Seam. Goaf was formed after the retreat of the protective coal seam started. The roof would collapse and floor would 


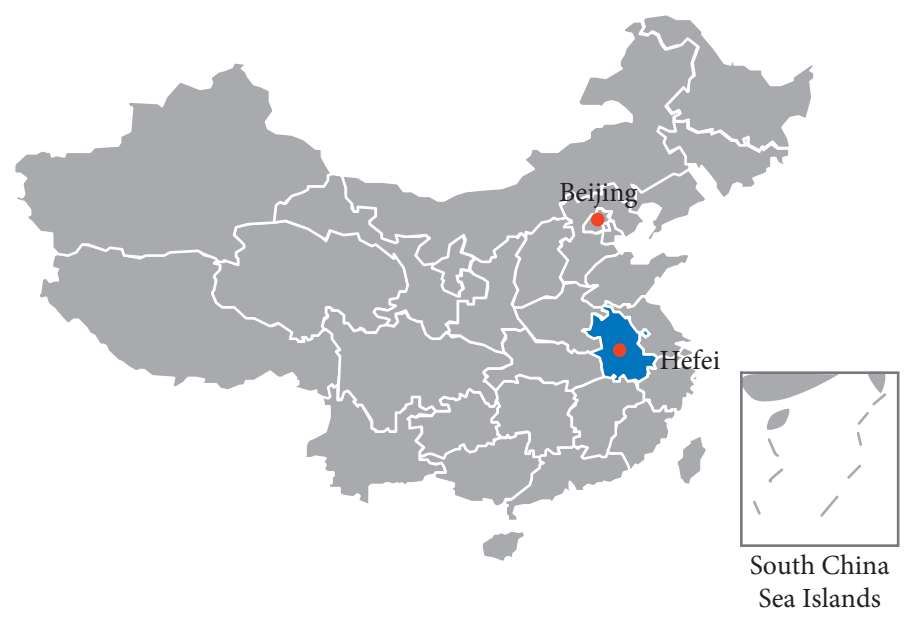

(a)

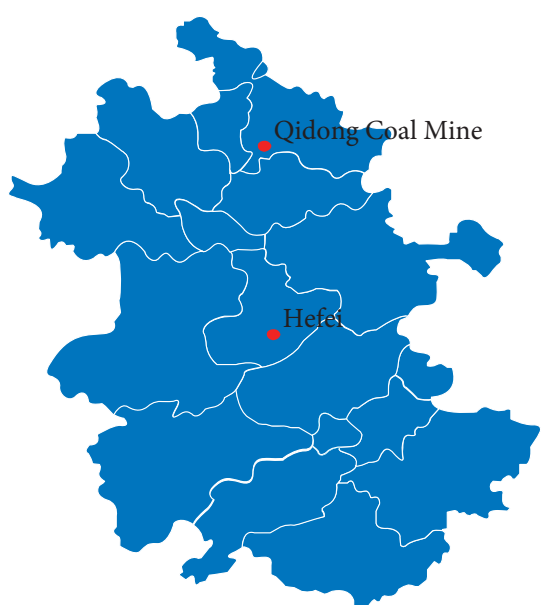

(b)

Figure 1: Location of Qidong Coal Mine.

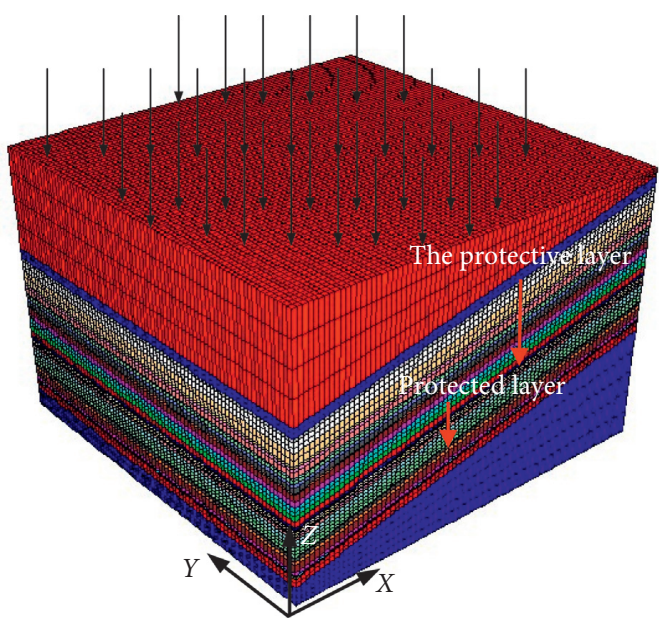

(a)

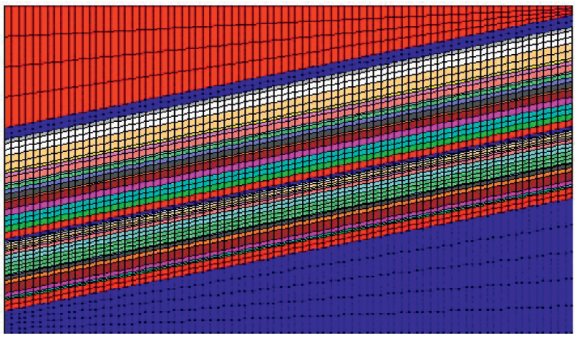

Inclination meshing

(c)

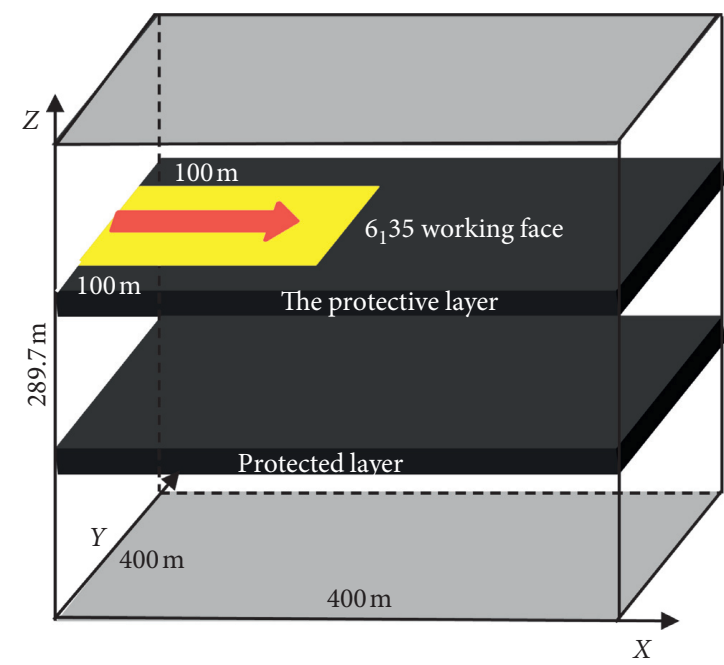

(b)

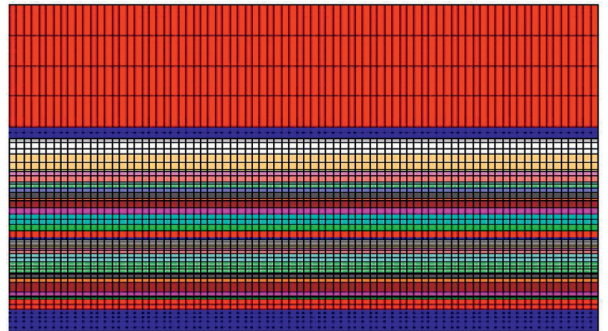

Towards meshing

(d)

Figure 2: Longwall panel 6 ,35 model.

heave significantly. Such failures at the roof and floor would have effect on the stress redistribution, permeability, outburst pressure, and deformation at the roof and floor of the seam. Therefore, investigation in these characteristics of the seam is very important.
The distribution of the vertical stress at the roof and floor of the seam after panel retreat is shown in Figures 3 and 4.

It can be seen from Figures 3 and 4 that the stress concentration tends to increase as the longwall face moves forward, and eventually, it tends to stabilize after longwall 
TABLE 1: Mechanical properties of various sediment rocks.

\begin{tabular}{|c|c|c|c|c|c|c|}
\hline Rock & $\begin{array}{l}\text { Volume modulus } \\
\qquad(\mathrm{K} / \mathrm{GPa})\end{array}$ & $\begin{array}{l}\text { Shear modulus } \\
\text { (G/GPa) }\end{array}$ & Tensile strength $\left(\sigma_{t} / \mathrm{MPa}\right)$ & $\begin{array}{l}\text { Cohesion } \\
(\mathrm{C} / \mathrm{MPa})\end{array}$ & Density $\left(\rho / \mathrm{kgm}^{-3}\right)$ & $\begin{array}{c}\text { Friction angle } \\
\varphi\left(^{\circ}\right)\end{array}$ \\
\hline Coal & 1.35 & 0.85 & 1 & 1.8 & 1400 & 27 \\
\hline Mudstone & 5.3 & 2.4 & 3.13 & 2.8 & 2703 & 29 \\
\hline Sandy mudstone & 8.1 & 7.9 & 2 & 2.4 & 2619 & 30 \\
\hline Medium sandstone & 10.2 & 17.7 & 4.6 & 7.8 & 2810 & 39.9 \\
\hline Medium-fine sandstone & 15.8 & 20.2 & 6.7 & 9.6 & 2710 & 35.3 \\
\hline Fine sandstone & 12.23 & 15.6 & 4.41 & 6.5 & 2606 & 35.4 \\
\hline
\end{tabular}

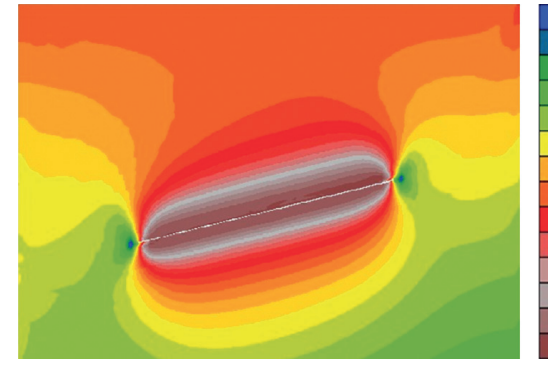

(a)

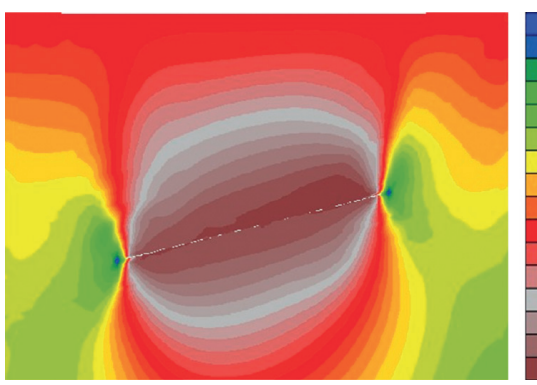

(c)

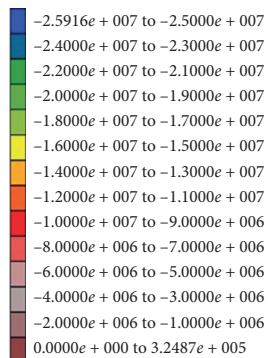

$2.9367 e+007$ to $-2.9000 e+007$ $-2.9367 e+007$ to $-2.9000 e+007$
$-2.8000 e+007$ to $-2.7000 e+007$ $-2.8000 e+007$ to $-2.7000 e+007$
$-2.6000 e+007$ to $-2.5000 e+007$ $-2.4000 e+007$ to $-2.3000 e+007$ $-2.2000 e+007$ to $-2.1000 e+007$ $-2.0000 e+007$ to $-1.9000 e+007$ $-1.8000 e+007$ to $-1.7000 e+007$ $-1.6000 e+007$ to $-1.5000 e+007$ $-1.4000 e+007$ to $-1.3000 e+007$ $-1.2000 e+007$ to $-1.1000 e+007$ $-1.0000 e+007$ to $-9.0000 e+006$ $8.0000 e+006$ to $-7.0000 e+006$ $-6.0000 e+006$ to $-5.0000 e+006$ $-4.0000 e+006$ to $-3.0000 e+006$ $2.0000 e+006$ to $-1.0000 e+006$ $0.0000 e+000$ to $4.2618 e+005$

along dip direction at various stae
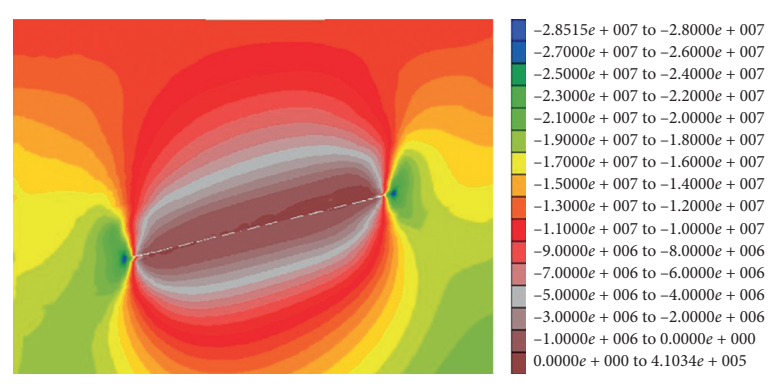

(b)

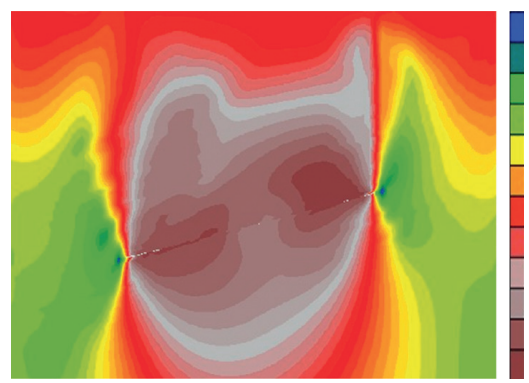

$-3.0179 e+007$ to $-3.0000 e+007$ $-2.8000 e+007$ to $-2.7000 e+007$ $-2.5000 e+007$ to $-2.4000 e+007$ $-2.2000 e+007$ to $-2.1000 e+007$ $-1.9000 e+007$ to $-1.8000 e+007$ $-1.6000 e+007$ to $-1.5000 e+007$ $-1.3000 e+007$ to $-1.2000 e+007$ $-1.0000 e+007$ to $-9.0000 e+006$ $-7.0000 e+006$ to $-6.0000 e+006$ $-4.0000 e+006$ to $-3.0000 e+006$ $-1.0000 e+006$ to $0.0000 e+000$ $0.0000 e+000$ to $5.1740 e+005$

(d)

FIGURE 3: Vertical stress distribution along dip direction at various stages of panel retreat. (a) Vertical stress distribution along dip direction after retreating $40 \mathrm{~m}$. (b) Vertical stress distribution along dip direction after retreating $80 \mathrm{~m}$. (c) Vertical stress distribution along dip direction after retreating $120 \mathrm{~m}$. (d) Vertical stress distribution along dip direction after retreating $200 \mathrm{~m}$.

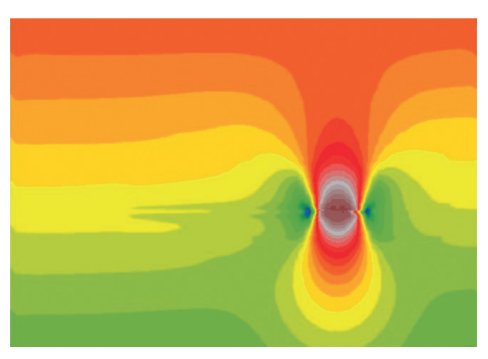

(a)

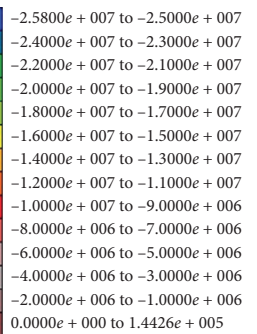

$-.0000 e+006$ to $-1.0000 e+006$
$0.0000 e+000$ to $1.4426 e+005$

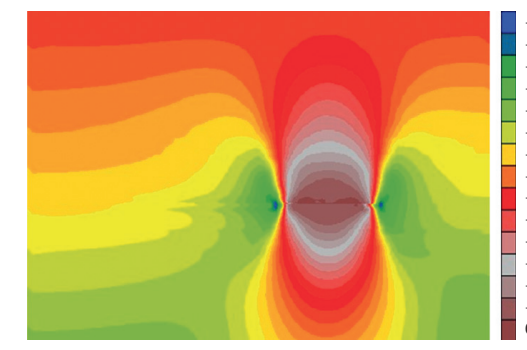

$-2.6982 e+007$ to $-2.6000 e+007$
$-2.5000 e+007$ to $-2.4000 e+007$
$-2.3000 e+007$ to $-2.2000 e+007$
$-2.1000 e+007$ to $-2.0000 e+007$
$-1.9000 e+007$ to $-1.8000 e+007$
$-1.7000 e+007$ to $-1.6000 e+007$
$-1.5000 e+007$ to $-1.4000 e+007$
$-1.3000 e+007$ to $-1.2000 e+007$
$-1.1000 e+007$ to $-1.0000 e+007$
$-9.0000 e+006$ to $-8.0000 e+006$
$-7.0000 e+006$ to $-6.0000 e+006$
$-5.0000 e+006$ to $-4.0000 e+006$
$-3.0000 e+006$ to $-2.0000 e+006$
$-1.0000 e+006$ to $0.0000 e+000$

(b)

FIgURE 4: Continued. 


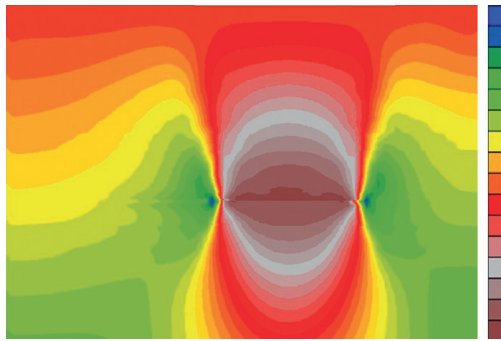

(c)

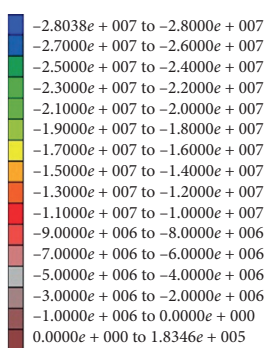

$0.0000 e+000$ to $1.8346 e+005$

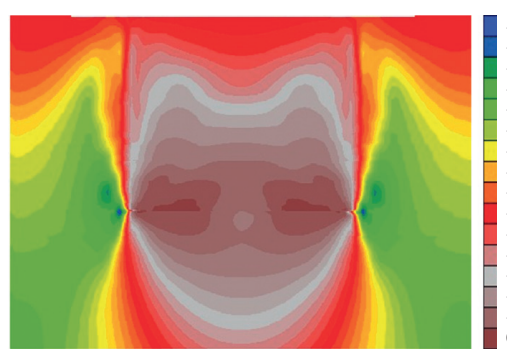

(d)

FIGURE 4: Vertical stress distribution along retreat direction at various retreat stages. (a) Vertical stress distribution along retreat direction after retreating $40 \mathrm{~m}$. (b) Vertical stress distribution along retreat direction after retreating $80 \mathrm{~m}$. (c) Vertical stress distribution along retreat direction after retreating $120 \mathrm{~m}$. (d) Vertical stress distribution along retreat direction after retreating $200 \mathrm{~m}$.

retreating for $120 \mathrm{~m}$. It should be noted that the vertical stress along the dip direction is higher than that along the retreat direction. The vertical stress distribution along the retreat direction is symmetric, whereas due to the dip angle, the stress distribution along the dip direction is asymmetric. In addition, the stress concentration at the two sides along the retreat direction and lower side along the dip direction tends to increase and the concentration area tends to expand during panel retreating.

As the face moves forward, the middle part at the floor tends to release the stress. It is subjected to a high tensile stress leading to heave behaviour on the floor. The extent of the stress relief at the floor tends to decrease as the depth of cover of the coal seam increases. The stress relief area tends to increase as the longwall face moves forward and eventually reaches a threshold value.

\subsection{Displacement in the Protective Coal Seam. Figure 5} shows the vertical displacement at the roof and floor of protected coal seam $7_{1}$ as the longwall face in the protective coal seam advances up to $200 \mathrm{~m}$. It can be seen from Figure 5(a) that the deformation distribution at the roof and floor at each retreating level is symmetric. The maximum vertical displacement at the roof in the goaf is $38.8 \mathrm{~mm}$, whereas the maximum displacement at the floor is $27.6 \mathrm{~mm}$. It can be seen from Figure $5(\mathrm{~b})$ that the maximum tensile displacement in the protected coal seam $7_{1}$ is $11.16 \mathrm{~mm}$ with the corresponding strain $7.86 \%$. During the protective coal seam mining operation, the roof above pillars tends to move downwards and at the vicinity of pillar, the displacement tends to move horizontally towards goaf area. On the contrary, the floor underneath pillars tends to downwards, and at the vicinity of the pillar on the floor, the rock on the floor tends to move horizontally towards goaf area due to the compression. In the goaf area, the underlying coal and rock tend to move upwards due to the compression and tension on the floor. This leads to the formation of the new cracks on the floor and increase in the openness of the existing cracks. As a result, the permeability of the coal seam increases and such a change would aid in the stress relief and gas drainage in the protected coal seam.
2.4. Division of Four Zones of the Trend of the Protected Coal Seam. Based on the analysis of the stress distribution in longwall panel $6_{1} 35$ of the protective coal seam during mining operation, the stress distribution in the underlying protected coal seam $7_{1}$ can be classified into four zones including original stress zone, stress concentration zone, stress relief zone, and recompaction zone (see Figure 6).

The area that is located over $38 \mathrm{~m}$ ahead of the longwall face is in the original stress zone. In such a zone, mining activity has negligible effect on the stress and strain in the protected coal seam $7_{1}$. The area that is located within 8 to $38 \mathrm{~m}$ ahead of the longwall face is in the stress concentration zone. In such a zone, the protected coal seam is subjected to high stress leading to the close of the fractures as well as reduction in permeability and gas flow. The area that is located from $8 \mathrm{~m}$ ahead of the longwall face to 70 behind the longwall face is in the stress relief zone. In such a zone, the protected coal seam is subjected to a lower stress leading to a large displacement as well as increase in the permeability and gas flow in the seam. As a result, the risk of coal and gas burst in this zone is low such that it would be more efficient to carry out the gas drainage work in this zone. The area that is located $70 \mathrm{~m}$ behind the longwall face is the recompaction zone. In such a zone, the fracture rocks that collapsed from the roof tend to compact and consolidate, leading to the stress recovering towards the original level. However, the stress after the recompaction is still less than the original level and it would take extensive time for the stress to come back to the original level.

In summary, during the retreat of the longwall panel 6,35 , the vertical displacement at the floor would follow three stages in sequence including significant increase and significant decrease followed by returning to the original level. This can be observed by compressive and tensile deformation at the floor of the roadway.

\section{Field Monitoring}

Four stress zones have been classified in the aforementioned numerical modelling work. In order to validate such a hypothesis, field monitoring was conducted in Qidong Coal Mine. Figure 7 shows the pattern of the borehole in protected coal seam $7_{1}$ for gas monitoring. 


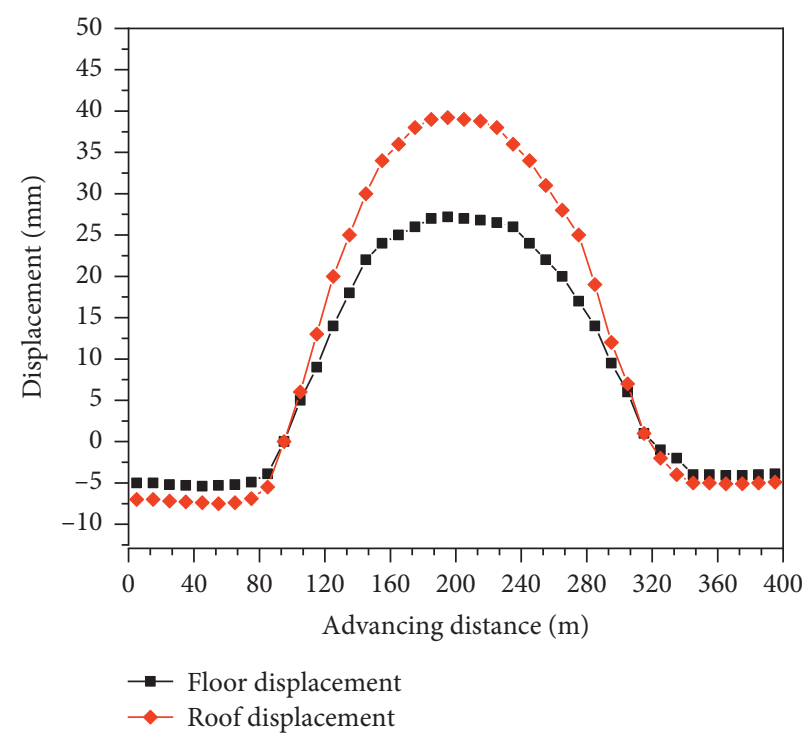

(a)

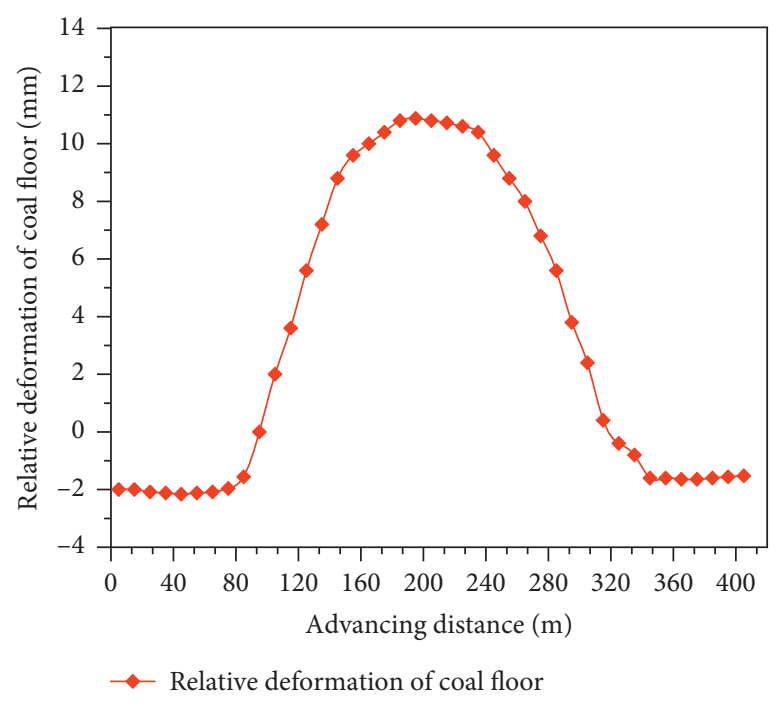

(b)

FIGURE 5: Displacement in the protected coal seam $7_{1}$ at various stages of longwall retreat. (a) Vertical displacement at the roof and floor of protected coal seam $7_{1}$ at various stages of longwall retreat. (b) Tensile displacement in the protected coal seam $7_{1}$ at various stages of longwall retreat.

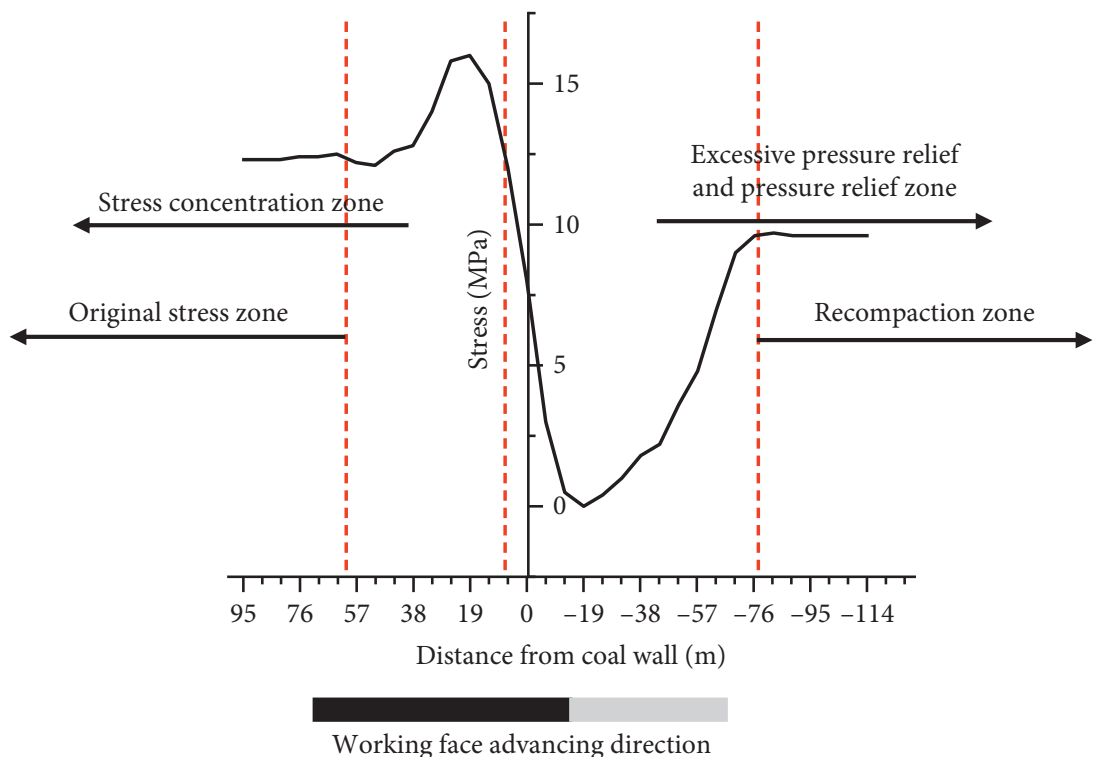

FIgURE 6: Stress distribution in protected coal seam 7 underneath the protective longwall panel 6135 .

The stress evolution in the protected coal seam $7_{1}$ follows four stages including original stress stage, stress concentration stage, stress relief stage, and recompaction stage. As a result, the gas concentration during the gas drainage would also vary correspondingly. The examples of gas concentration and flow quantity data in a number of selected boreholes are shown in Figures 8-12.

A few remarks can be concluded based on Figures 8 and 9.

(1) For the boreholes located over $20 \mathrm{~m}$ ahead of the longwall face of the longwall panel 6,35 in the protective coal seam, the gas concentration monitored fluctuated significantly in the range between $5 \%$ and $85 \%$, whereas the flow quantity remains low in the range of 0.01 to $0.06^{3} \mathrm{~min}$. It could be observed that the gas drainage performance in this area is not optimized and the protected coal seam $7_{1}$ was subjected to original stress condition.

(2) For the boreholes located between 8 to $20 \mathrm{~m}$ ahead of the longwall face of the longwall panel 6,35 in the protective coal seam, the gas concentration monitored reduced significantly to $15 \%$ and the flow 


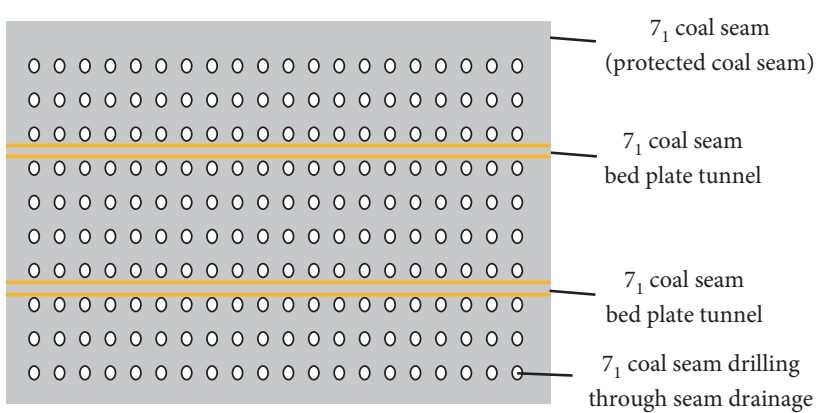

(a)

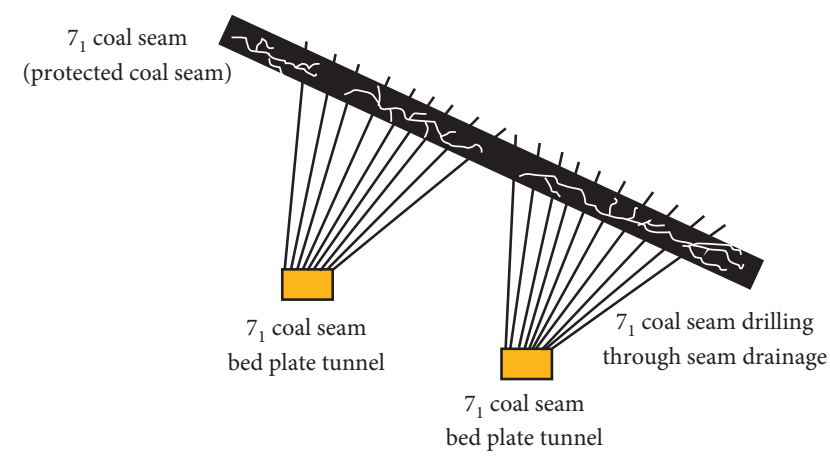

(b)

FIGURE 7: Borehole pattern in protected coal seam 7 . (a) Plan view of borehole pattern in protected coal seam $7_{1}$. (b) Cross-sectional view of borehole drilling.

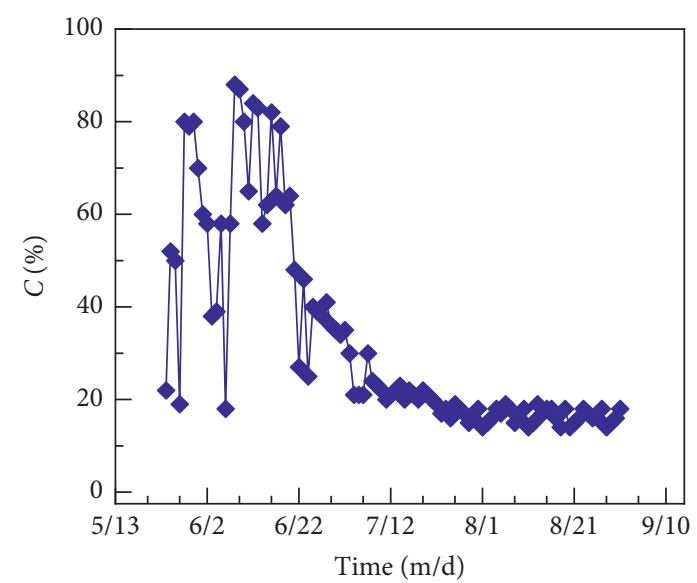

(a)

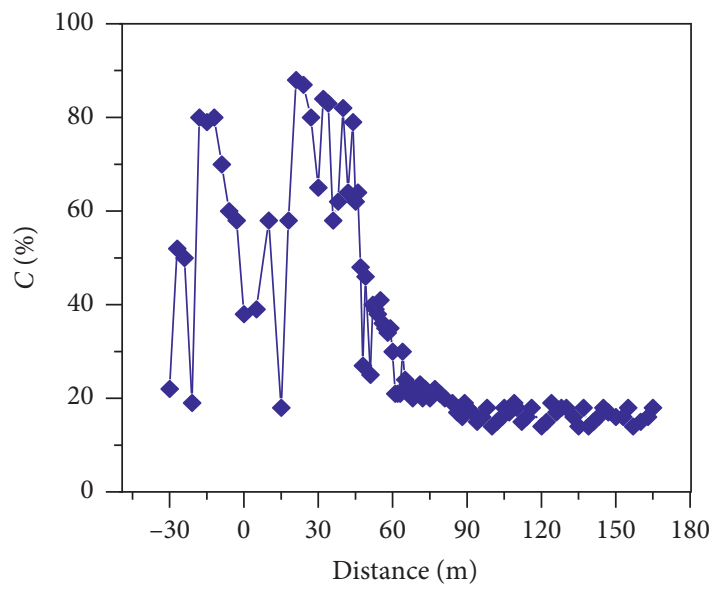

(c)

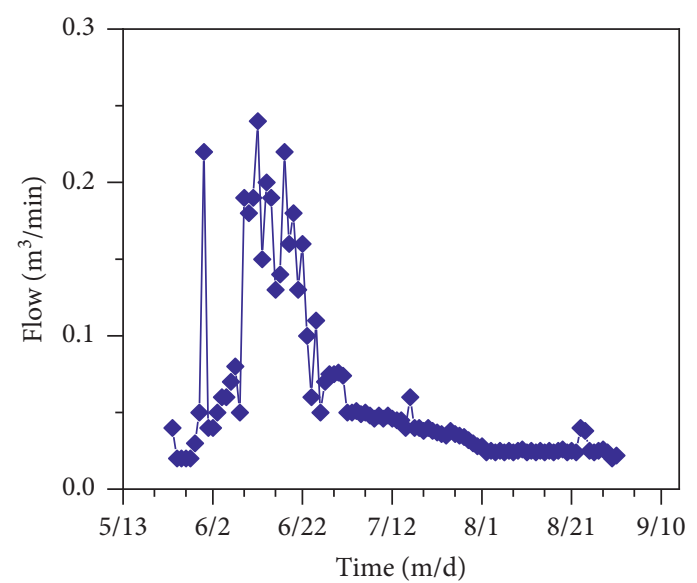

(b)

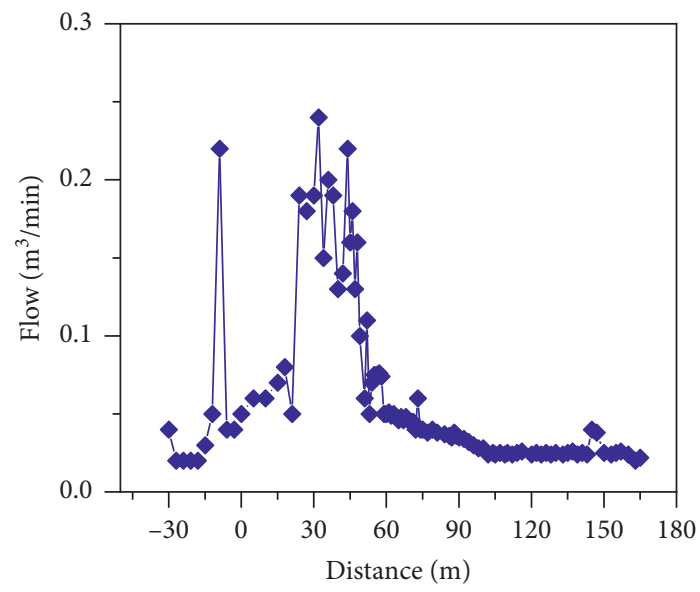

(d)

FIGURE 8: Gas monitoring data in no. 1 borehole of group 14.

quantity remains low in the range of 0.03 to $0.05^{3} \mathrm{~min}$. It could be observed that the protected coal seam $7_{1}$ was subjected to stress concentration condition.

(3) For the boreholes located between 8 ahead of the longwall face and $55 \mathrm{~m}$ behind the longwall face in the protective coal seam, the gas concentration monitored increased significantly up to $100 \%$ and the flow quantity also increased significantly to the range of 0.2 to $0.3^{3} \mathrm{~min}$. It could be observed that the protected coal seam $7_{1}$ was subjected to stress relief condition.

(4) For the boreholes located over $55 \mathrm{~m}$ behind the longwall face in the protective coal seam, the gas 


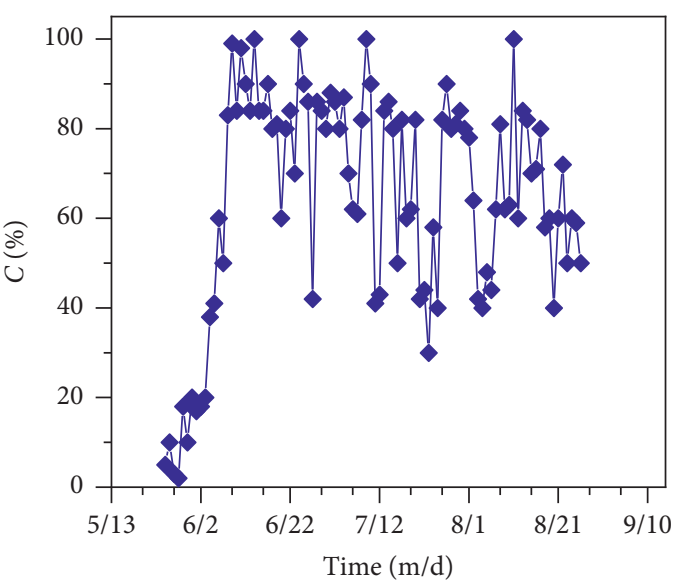

(a)

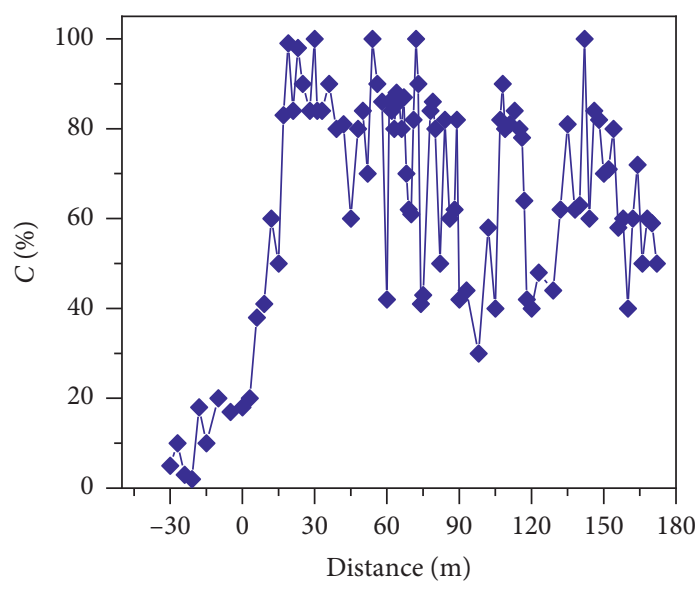

(c)

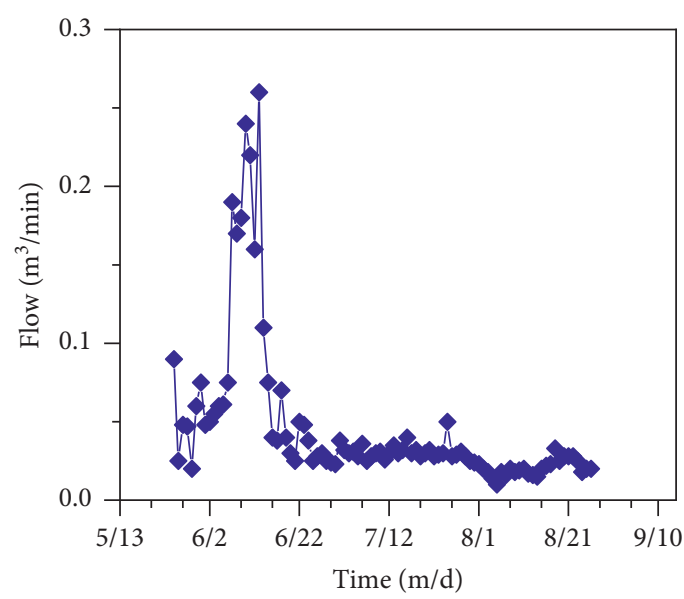

(b)

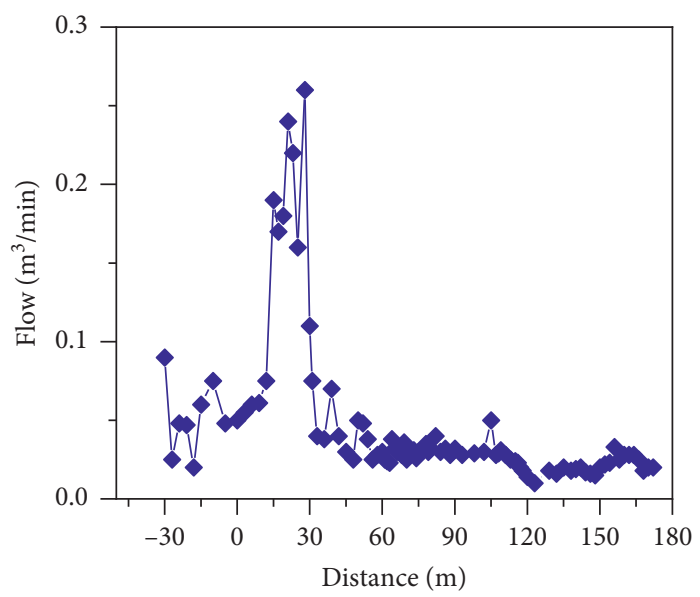

(d)

FIgURE 9: Gas monitoring data in no. 2 borehole of group 14.

concentration monitored was lower than $40 \%$ and the flow quantity reduced to the range of 0.02 to $0.06^{3} \mathrm{~min}$. It could be observed that the protected coal seam $7_{1}$ was subjected to recompaction condition.

Three more sets of gas monitoring data shown in Figures 10-12 were used to further validate the gas monitoring data seen in Figures 8 and 9. As a result, the area of each of the four stress distribution zones was further calibrated based on the field monitoring data and numerical modelling results.

(1) For the boreholes located 20 to $25 \mathrm{~m}$ ahead of the longwall face in the protective coal seam $6_{1}$, the protected coal seam 71 was subjected to original stress condition. Such an area is only $13 \mathrm{~m}$ different to that determined by numerical modelling. In this area, the gas concentration fluctuated significantly in the range of $1 \%$ to $85 \%$, whereas the flow quantity remained low in the range of 0.01 to $0.05 \mathrm{~m}^{3} / \mathrm{min}$. It could confirm that the gas drainage performance would not be optimized in this area.
(2) For the boreholes located 5 to $20 \mathrm{~m}$ ahead of the longwall face in the protective coal seam $6_{1}$, the protected coal seam $7_{1}$ was subjected to stress concentration condition. Such an area is only 2 to $10 \mathrm{~m}$ different to that determined by numerical modelling. In this area, the gas concentration reduced significantly to $15 \%$ and the flow quantity remained low in the range of 0.03 to $0.06 \mathrm{~m}^{3} / \mathrm{min}$. It could confirm that the gas drainage performance would not be optimized in this area.

(3) For the boreholes located between $5 \mathrm{~m}$ ahead of the longwall face and $65 \mathrm{~m}$ behind the longwall face in the protective coal seam $6_{1}$, the protected coal seam 7 was subjected to stress relief condition. Such an area is only $5 \mathrm{~m}$ different to that determined by numerical modelling. In this area, the gas concentration surged significantly up to $100 \%$ and the flow quantity also increased significantly up to the range of 0.1 to $0.3 \mathrm{~m}^{3} / \mathrm{min}$. It could confirm that the gas drainage performance in this area is optimal.

(4) For the boreholes located over $65 \mathrm{~m}$ behind the longwall face in the protective coal seam $6_{1}$, the 


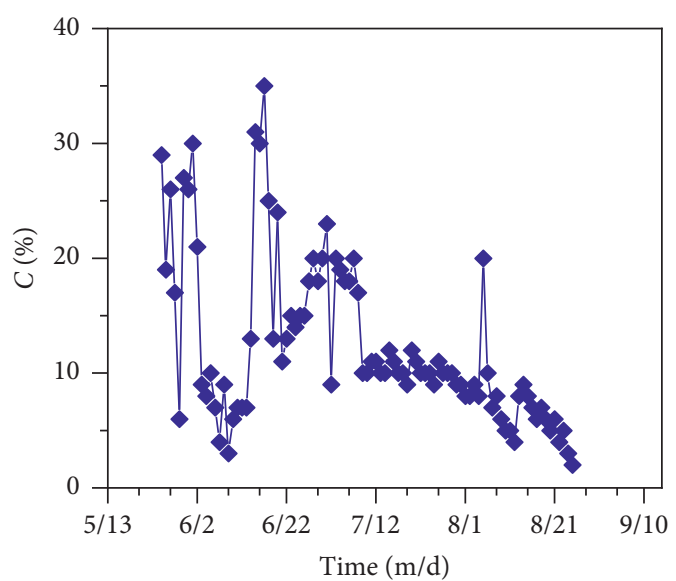

(a)

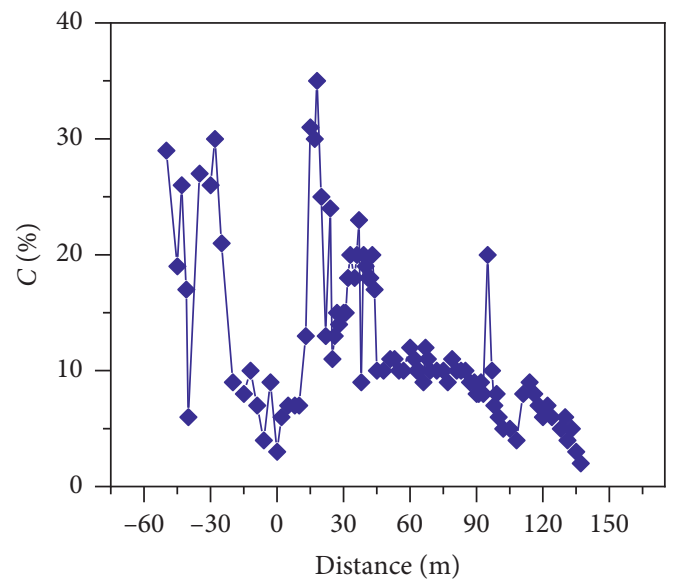

(c)

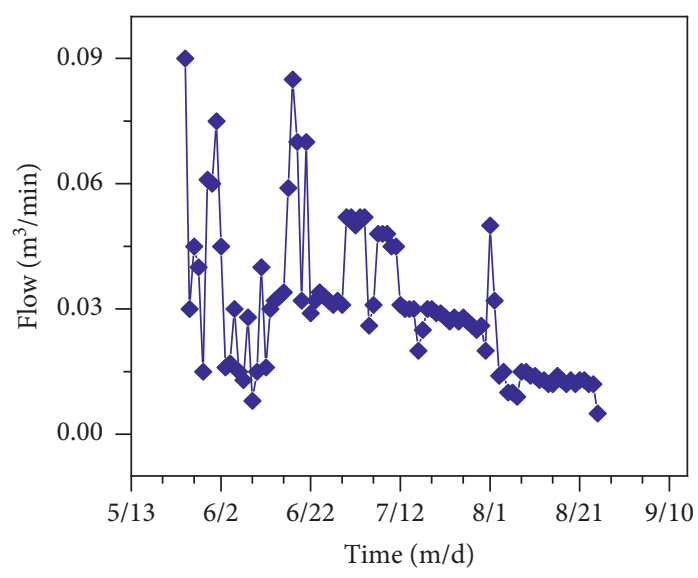

(b)

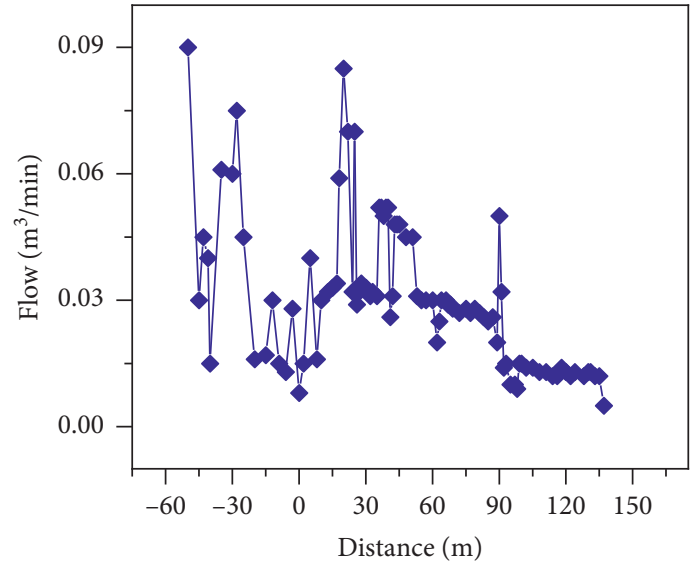

(d)

FIgURe 10: Gas monitoring data in no. 1 borehole of group 15.

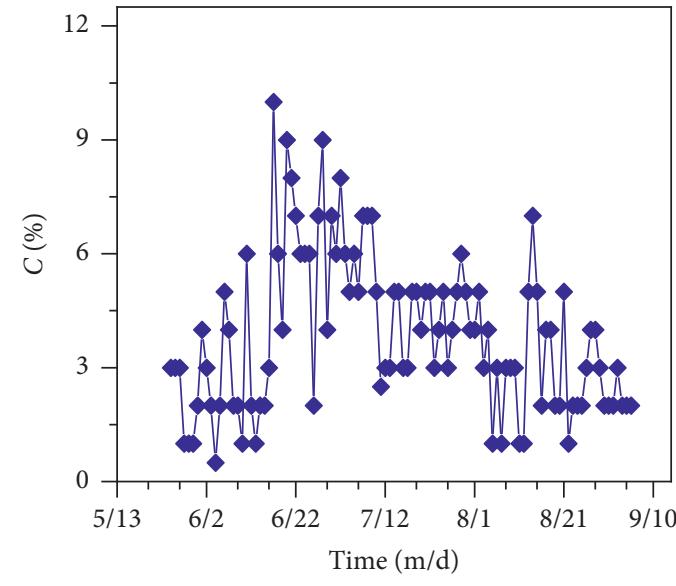

(a)

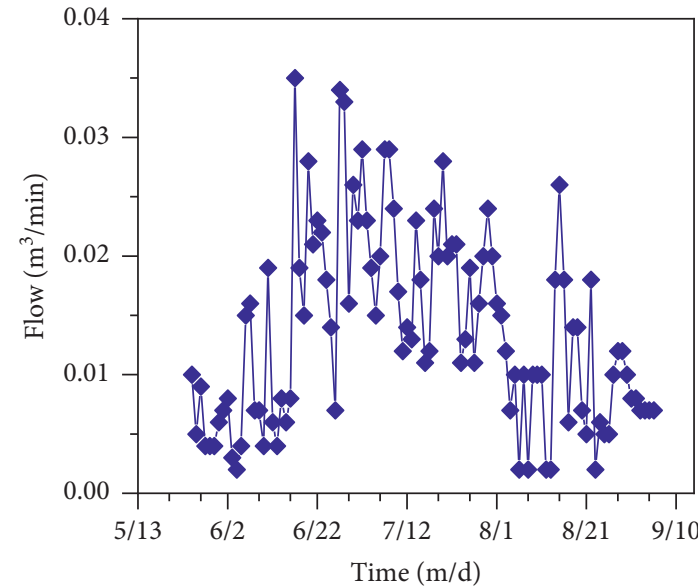

(b)

Figure 11: Continued. 


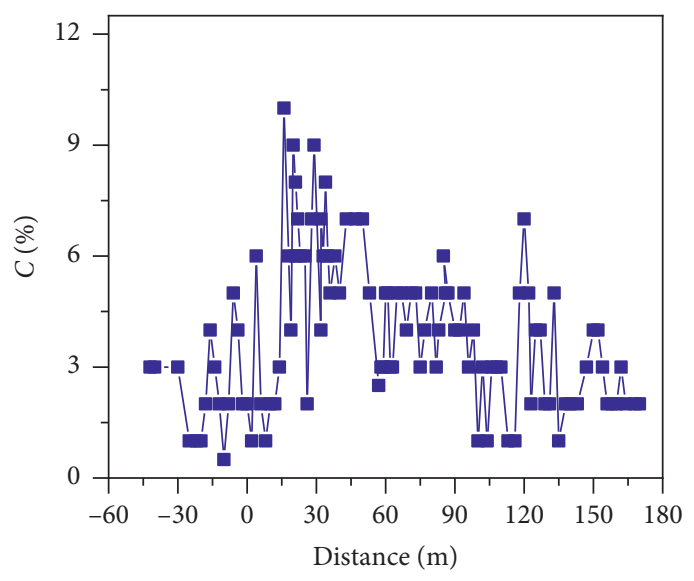

(c)

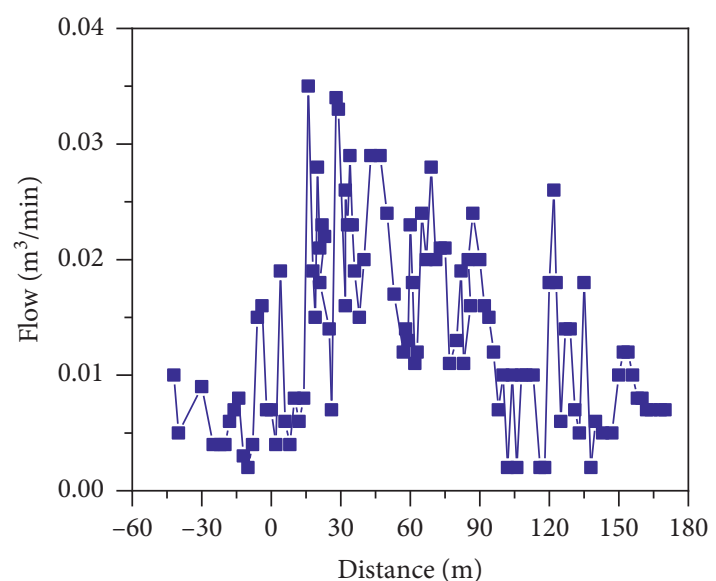

(d)

FIgURe 11: Gas monitoring data in no. 1 borehole of group 16.

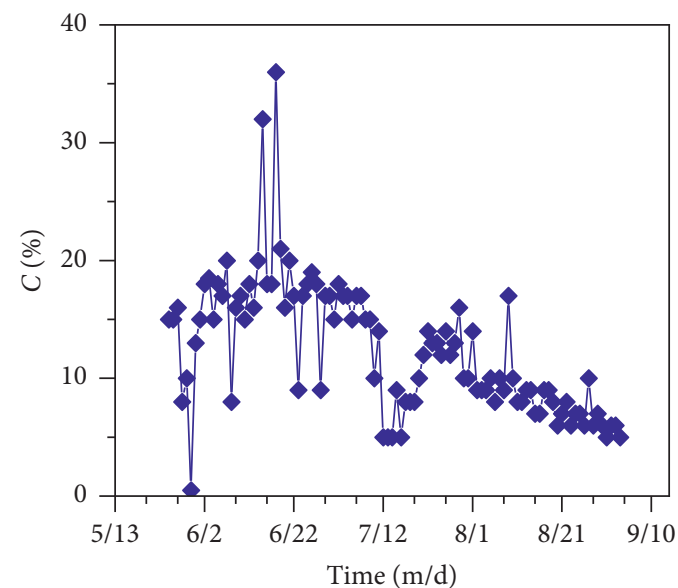

(a)

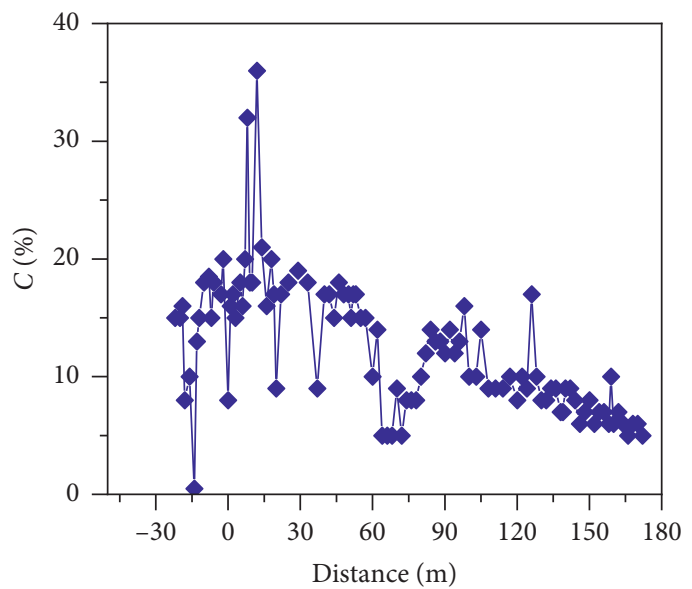

(c)

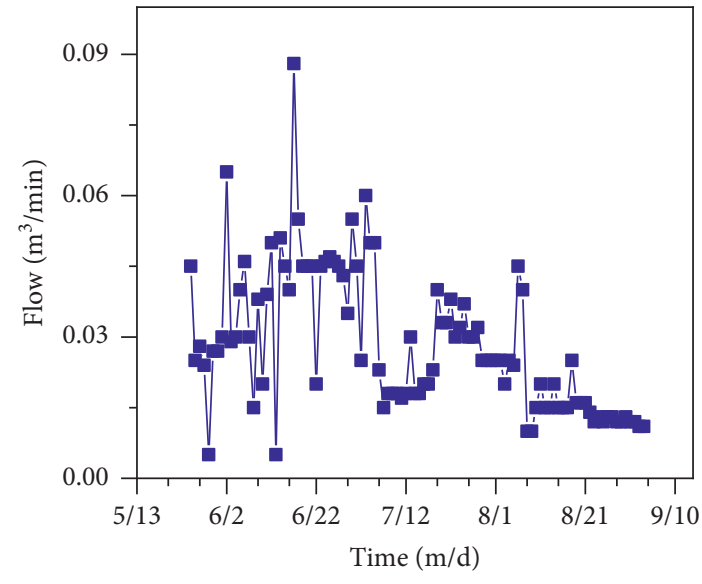

(b)

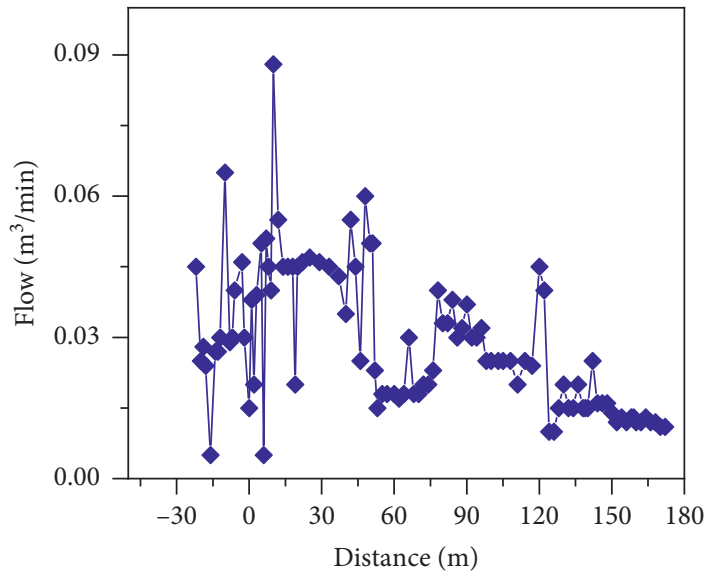

(d)

FIgURE 12: Gas monitoring data in no. 1 borehole of group 18.

protected coal seam $7_{1}$ was subjected to recompaction condition. Such an area is only $5 \mathrm{~m}$ different to that determined by numerical modelling. In this area, the gas concentration was lower than $30 \%$ and the flow quantity also reduced to the range of 0.01 to $0.05 \mathrm{~m}^{3} / \mathrm{min}$. 


\section{Conclusions and Outlook}

Using numerical simulation to get the upper protective layer under mining effect, it is found that under the action of upper protective layer mining, the strike upper web stress contour is symmetrical saddle-shaped distribution. The stress of the bottom plate is distributed in an "eight" shape with a small top and a big bottom, and the vertical stresses of the top and bottom plates are distributed asymmetrically.

After the protection layer is mined, the coal and rock under the goaf moved upward as a whole, and the maximum swelling deformation reached $4.29 \%$, which expanded the original fissures and formed new fissures, creating conditions for the pressure relief gas drainage of the protected layer.

Based on the stress distribution results of the numerical simulation, the range of the strike "four zones" of the protected coal seam 7 was divided, and field verification was carried out. The range of the strike "four zones" was revised according to the gas drainage effect of the protected layer.

As an economical and effective technical means to prevent coal and gas outburst, protective layer mining has been studied more and more in recent years, and research methods have become more and more abundant, which has promoted the rapid development of protective layer mining theory. However, there is currently little research on the combined mining of the upper protective layer and the lower protective layer. With the continuous maturity of protective layer mining technology and the development of theory, under the superimposed effect of the combined mining of the lower protective layer and the upper protective layer, the temporal and spatial changes of coal seams, surrounding rock stress, and interlayer deformation will gradually become the focus of future research.

\section{Data Availability}

The data used to support the findings of this study are available from the corresponding author upon request.

\section{Conflicts of Interest}

The authors declare that they have no conflicts of interest.

\section{Acknowledgments}

This work was financially supported by the National Key Research and Development Program of China (nos. 2017YFC0804206 and 2017YFC0804209) and the Anhui Provincial Natural Science Foundation (no. 2008085ME147).

\section{References}

[1] G. Fu, X. Xie, Q. Jia, W. Tong, and Y. Ge, "Accidents analysis and prevention of coal and gas outburst: understanding human errors in accidents," Process Safety and Environmental Protection, vol. 134, pp. 1-23, 2020.
[2] K. Nilufer and O. Mustafa, "Application of structural equation modeling to evaluate coal and gas outbursts," Tunnelling and Underground Space Technology, vol. 88, pp. 63-72, 2019.

[3] D. J. Black, "Review of coal and gas outburst in Australian underground coal mines," International Journal of Mining Science and Technology, vol. 29, no. 6, pp. 815-824, 2019.

[4] L. Wang, X. Chen, Z. Wang, S. Xu, and Q. Xu, "Extending the protection range in protective seam mining under the influence of gas drainage," Journal of the Southern African Institute of Mining and Metallurgy, vol. 120, no. 3, 2020.

[5] H. Wang, Y. Cheng, and L. Yuan, "Gas outburst disasters and the mining technology of key protective seam in coal seam group in the Huainan coalfield," Natural Hazards, vol. 67, no. 2, pp. 763-782, 2013.

[6] H.-D. Chen, C. Yuan-Ping, H.-X. Zhou, and W. Li, "Damage and permeability development in coal during unloading," Rock Mechanics and Rock Engineering, vol. 46, no. 6, pp. 1377-1390, 2013.

[7] Y. Zhou, Z. Li, Y. Yang et al., "Effect of adsorption-induced matrix deformation on coalbed methane transport analyzed using fractal theory," Journal of Natural Gas Science and Engineering, vol. 26, pp. 840-846, 2015.

[8] S. Wang, Y. Cheng, and W. Li, "Model development and analysis of the evolution of coal permeability under different boundary conditions," Journal of Natural Gas Science and Engineering, vol. 31, pp. 129-138, 2016.

[9] N. N. Danesh, Z. Chen, S. M. Aminossadati, M. S. Kizil, Z. Pan, and L. D. Connell, "Impact of creep on the evolution of coal permeability and gas drainage performance," Journal of Natural Gas Science and Engineering, vol. 33, pp. 469-482, 2016.

[10] K. Jin, Y. Cheng, W. Wang, H. Liu, Z. Liu, and H. Zhang, "Evaluation of the remote lower protective seam mining for coal mine gas control: a typical case study from the Zhuxianzhuang Coal Mine, Huaibei Coalfield, China," Journal of Natural Gas Science and Engineering, vol. 33, pp. 44-55, 2016.

[11] Y. Yuan, Z. S. Chen, X. W. Zhang, and Z. H. Wang, "Intermediate coal pillar instability and permeability evolution in extremely thin protective seam by auger mining," Arabian Journal of Geosciences, vol. 12, no. 10, 2019.

[12] D. Li, "Mining thin sub-layer as self-protective coal seam to reduce the danger of coal and gas outburst," Natural Hazards, vol. 71, no. 1, pp. 41-52, 2014.

[13] L. Wang, Z. Lu, D. P. Chen et al., "Safe strategy for coal and gas outburst prevention in deep-and-thick coal seams using a soft rock protective layer mining," Safety Science, vol. 129, 2020.

[14] A. He, H. Fu, B. Huo, and C. Fan, "Permeability enhancement of coal seam by lower protective layer mining for gas outburst prevention," Shock and Vibration, vol. 2020, pp. 1-12, Article ID 8878873, 2020.

[15] Z. Yuan, Y. Shao, and Z. Zhu, "Similar material simulation study on protection effect of steeply inclined upper protective layer mining with varying interlayer distances," Advances in Civil Engineering, vol. 2019, pp. 1-14, Article ID 9849635, 2019.

[16] B. M. Shi and Z. G. Liu, "Numerical simulation of the upper coal and rock deformation characteristic caused by mining protecting stratum," Journal of China Coal Society, vol. 19, no. 3, pp. 276-281, 2008.

[17] F. Fang, C. Shu, and H. Wang, "Physical simulation of upper protective coal layer mining with different coal seam inclinations," Energy Science \& Engineering, vol. 8, no. 9, pp. 3103-3116, 2020. 
[18] J. Qin, Q. Qingdong, and H. Guo, "CFD simulations for longwall gas drainage design optimisation," International Journal of Mining Science and Technology, vol. 27, no. 5, pp. 777-782, 2017.

[19] Z. Cao, X. He, E. Wang, and B. Kong, "Protection scope and gas extraction of the low-protective layer in a thin coal seam: lessons from the DaHe coalfield, China," Geosciences Journal, vol. 22, no. 3, pp. 487-499, 2018.

[20] D. J. Xue, H. W. Zhou, L. Kong et al., "Mechanism of unloading-induced permeability increment of protected coal seam under mining," Chinese Journal of Geotechnical Engineering, vol. 34, no. 10, pp. 1910-1916, 2012.

[21] Z. Q. Wang, R. M. Feng, Y. Gao, P. F. Li et al., "Research on mining technology of nether protective seam in inclined contiguous seams with continuous pressure-relief on outburst coal seam," Chinese Journal of Geotechnical Engineering, vol. 32, no. S2, pp. 3795-3803, 2013.

[22] H. Zhang, Z. Wen, B. Yao, and X. Chen, "Numerical simulation on stress evolution and deformation of overlying coal seam in lower protective layer mining," Alexandria Engineering Journal, vol. 59, no. 5, pp. 3623-3633, 2020. 